\title{
Review of the safety, efficacy, and side effect profile of asenapine in the treatment of bipolar I disorder
}

\author{
This article was published in the following Dove Press journal: \\ Patient Preference and Adherence \\ 30 June 2011 \\ Number of times this article has been viewed
}

\author{
Jodi M Gonzalez' \\ Peter MThompson' \\ Troy A Moore ${ }^{1,2}$ \\ 'University of Texas Health Science \\ Center, San Antonio, TX, USA; ${ }^{2}$ South \\ Texas Veterans Health Care System, \\ TX, USA
}

Objective: Asenapine is approved for acute manic and mixed states in bipolar disorder. The objective is to review the efficacy of asenapine in bipolar disorder, with a particular focus on acceptability and adherence to treatment.

Methods: Five clinical trials were conducted in bipolar disorder manic or mixed states: two 3-week trials $(n=976)$ comparing asenapine to placebo, a 9-week extension $(n=504)$, and a 40 -week extension $(n=107)$. One trial was conducted comparing asenapine to placebo $(n=326)$ as adjunctive therapy for subjects with an incomplete response to lithium or valproate. All trials were conducted in the USA and internationally.

Results: Asenapine was found to be efficacious for manic and mixed states in bipolar disorder compared with placebo control, and compares equally well to olanzapine on efficacy measures after 3 weeks of treatment. Asenapine was not found to be efficacious for depression symptoms. Common asenapine side effects in the 40 -week extension trial were sedation, insomnia, and dizziness, and $31 \%$ reported clinically significant weight gain, compared with $55 \%$ reporting clinically significant weight gain with olanzapine. Additionally, $18 \%$ had clinically significant changes in fasting blood glucose levels compared to $22 \%$ of those on olanzapine. In terms of patient acceptability, one concern may be sublingual administration requiring no liquids or food for 10 minutes after dosing and a twice-daily regimen. Suggestions about addressing barriers to adherence and acceptability are provided.

Conclusion: Asenapine is a promising new medication in bipolar disorder. Asenapine in the long-term has a more favorable weight gain profile compared to olanzapine. No benefit was seen for depression symptoms, a major patient-reported concern. Some side effects do not remit after the short-term trials in at least $10 \%$ of patients.

Keywords: asenapine, antipsychotic, adherence, acceptability, metabolic syndrome

\section{Introduction}

\section{Adherence to medication in bipolar disorder}

Treatment guidelines in bipolar disorder recommend ongoing pharmacological treatment for individuals who have had more than one mood episode. ${ }^{1,2}$ As bipolar disorder is a chronic illness, it is imperative that medication to treat its symptoms and prevent relapse are acceptable to patients not only during acute phases, but also during the long-term course of the illness.

Medication adherence estimates in bipolar disorder vary across studies based on definitions of adherence, length of follow up, and the population studied, averaging $30 \%-50 \% .^{3-7}$ As with most chronic illnesses, adherence to medication regimens is a major focus in clinical and research settings. ${ }^{3,8}$ Nonadherence to medications can
Correspondence: Jodi M Gonzalez 7703 Floyd Curl Drive, San Antonio, TX 78229, USA

Tel + I 2105675424

Fax + I 2105673759

Email gonzalezjm I@uthscsa.edu 
result in severe symptoms and increased mood episodes, increased psychiatric hospitalizations, and suicidality. ${ }^{3,8,9}$ Most of the bipolar disorder adherence literature has examined attitudes toward lithium, a primary mood-stabilizing medication intervention, ${ }^{5,710}$ with valproic acid and second generation antipsychotics also providing mood-stabilizing effects. Doctors and patients must make collaborative decisions about the benefit to risk ratios of potential medications to treat bipolar disorder. ${ }^{11,12}$

Velligan et al provide a comprehensive review of factors contributing to nonadherence in bipolar disorder. ${ }^{8}$ Demographic factors, particularly younger age or being of ethnic minority status, deficits in cognitive functioning, and logistical problems interfering with medication routines (eg, housing, financial, chaotic social environment) decrease adherence. Poor insight into one's illness or into the need for medication, or negative attitudes toward medications can negatively impact adherence. Co-occurring substance abuse, a poor quality therapeutic relationship, and minimal social support are other factors. ${ }^{8}$ One concern specific to bipolar disorder is that patients with bipolar disorder might view antipsychotics as more stigmatizing than mood stabilizers. ${ }^{13}$ Medication helpful in treating depression can positively impact adherence. ${ }^{14}$ Persons with bipolar disorder note that the top two areas of concern in their patient care are medications that provide less risk of weight gain and better treatment for depression. ${ }^{15}$ As for reasons for nonadherence to antipsychotics in particular, medication side effects can be a major factor.

\section{Adherence in antipsychotic medication}

Side effects most often associated with antipsychotic medications include somnolence, sedation, insomnia, dizziness, headaches, gastrointestinal symptoms, sexual dysfunction, and extrapyramidal symptoms (EPS). The metabolic and weight gain side effects associated with antipsychotics may be the biggest contributors to nonadherence due to side effects. ${ }^{16}$ That is, increased adiposity, increased blood pressure, abnormal cholesterol, and triglyceride levels and insulin resistance, which can lead to increased rates of diabetes and heart disease. ${ }^{16}$ In a recent report, the medication side effect reported most often among 1155 persons with schizophrenia and 1300 persons with bipolar disorder was weight gain. ${ }^{15}$

Antipsychotics are now prescribed in approximately $45 \%$ of patients in the medication management of bipolar disorder. ${ }^{9}$ Six antipsychotic medications have been FDA-approved to treat various phases of bipolar disorder, with asenapine $\left(\right.$ Saphris $^{\circledR}$, Merck and Co, IncKenilworth, NJ) being the most recent FDA approval in August 2009. In this paper, we describe the efficacy, tolerability, and side effect profile of asenapine, with a particular focus on tolerability and long-term side effects. We will compare these data with side effect profiles of other FDA approved antipsychotics in bipolar disorder. We will provide clinical suggestions for when asenapine should be considered for treatment of manic or mixed episodes.

\section{Asenapine Overview}

Asenapine is an atypical antipsychotic indicated for the treatment of schizophrenia and for the acute treatment of manic or mixed episodes, with or without psychotic features, associated with bipolar disorder. Asenapine is approved as monotherapy and as adjunctive therapy. The initial recommended dose of asenapine monotherapy for bipolar disorder is $20 \mathrm{mg}$ total daily dose (10 mg sublingually twice daily), which is also the recommended target dose. For adjunctive therapy, the recommended dose is $10-20 \mathrm{mg}$. The safety of total daily doses above $20 \mathrm{mg}$ has not been evaluated in clinical trials. Ninety percent of bipolar patients in registration trials required $10 \mathrm{mg}$ twice daily for a clinical response.

\section{Pharmacology/pharmacokinetics}

The exact mechanism by which asenapine reduces manic symptoms associated with bipolar disorder is unknown. Asenapine has high affinity for serotonin receptors (5-HT1a, 5-HT1b, 5-HT2a, 5-HT2b, 5-HT2c, 5-HT5, 5-HT6, and 5-HT7), dopamine receptors (D1, D2, D3, and D4), Alpha 1 and 2 receptors, and histamine (H1) receptors. It also has moderate affinity for histamine (H2) receptors. Asenapine acts as an antagonist at all these receptors. Unlike some other antipsychotics (eg, olanzapine) asenapine has no appreciable binding to muscarinic receptors. The mean halflife of asenapine is 24 hours and steady state concentrations are achieved in 3 days with multiple dosing. Absorption pharmacokinetics are very important with asenapine as the absolute bioavailability of asenapine taken sublingually is approximately $35 \%$, but if swallowed the bioavailability is less than $2 \% .{ }^{17}$ Patients must be properly counseled on the importance of taking asenapine sublingually with no drinking or eating 10 minutes after administration. Asenapine is metabolized via direct glucuronidation by UGT1A4 and oxidative metabolism by cytochrome P450 isoenzymes (predominantly CYP1A2). 


\section{Efficacy}

Efficacy studies of asenapine have included two 3-week trials, a 9-week extension trial, a 40-week extension trial, and a 52-week adjunctive therapy trial. ${ }^{18-22}$ The 3-week trials resulted in FDA approval (ARES 7501004, ARES 7501005), involved 976 subjects across 62 centers internationally, and had similar research designs. Subjects were randomized to receive flexible dosing asenapine $5-10 \mathrm{mg}$ bid $(\mathrm{n}=379)$, olanzapine $2-20 \mathrm{mg} / \mathrm{d}(\mathrm{n}=395)$, or placebo $(\mathrm{n}=202)$. Subjects had a diagnosis of bipolar I disorder with a current manic or mixed episode and a Young Mania Rating Scale $(\text { YMRS })^{23}$ score $\geq 20$. Excluded subjects included those with current substance abuse, "clinically significant medical conditions or laboratory abnormalities," and rapid cycling bipolar disorder.

The studies were single blind placebo run-in for 7 days, where all psychiatric medications were discontinued in an inpatient setting except for benzodiazepines, nonbenzosedative hypnotics, and medications used to treat EPS. Benzodiazepines and sleep enhancers were used for agitation or insomnia and were discontinued by day 7 , and every effort was made to discontinue medication used to treat EPS. Subjects were then randomized to asenapine, olanzapine, or placebo for 21 days. Subjects remained inpatients for 7 or more days and the trial then continued on an outpatient basis if clinically indicated. The mean daily dose of asenapine across trials was $18.3 \pm 3 \mathrm{mg}$. Both trials showed a significant reduction in YMRS scores for asenapine compared to baseline scores at day 21; average change across the two studies was -11 for asenapine, -14 for olanzapine, and -7 for placebo. The effect size of change for olanzapine was significantly greater than for asenapine in study $7501004 .{ }^{19}$ For secondary outcomes, the Clinical Global Impression for Bipolar Disorder mania severity score $^{24}$ (CGI-BP) was similarly reduced. The MontgomeryAsberg Depression Rating Scale ${ }^{25}$ was significantly reduced only for olanzapine compared with placebo at day 21 for both trials. Trial 7501005 reported significant differences from placebo in response ( $\geq 50 \%$ reduction in YMRS) and remission (YMRS $\leq 12$ ), while there were no differences in 7501004 (see Table 2). Olanzapine differed from placebo on secondary outcomes for both trials.

When subjects completed the 3-week trial they were eligible to participate in a 9-week blinded extension study. ${ }^{22}$ Subjects remained on the same nonplacebo treatment as the 3-week trial and the placebo group was assigned to asenapine. Inclusion and exclusion criteria were similar to the 3-week trial criteria. Five hundred and four subjects participated $($ placebo/asenapine $=94$, asenapine $=181$, and olanzapine $=229$ ). Each group continued to improve on manic symptoms. At study end on day 84 (including the 3-week-trial days), both the asenapine and olanzapine groups had significant reductions in YMRS ( -24.4 asenapine and -23.9 olanzapine) with no significant differences between asenapine and olanzapine. There were no significant differences between the rates of response ( $\geq 50 \%$ reduction in YMRS, 90\%, 92\%) and remission (YMRS $\leq 12,88 \%$, $91 \%$ ) for asenapine and olanzapine, respectively. Less than $2 \%$ of subjects in any group showed significant worsening of manic symptoms. With secondary outcomes, at day 84 there was no significant difference between asenapine and olanzapine for MADRS (change scores: asenapine $=-2.6$, olanzapine $=-2.4$ ) and CGI-BP scores (change score: asenapine $=-3.6$, olanzapine $=-2.4$ ). Using overall CGI-BP illness scores, $3 \%$ of the asenapine and $7 \%$ of the olanzapine group had higher (worse) CGI-BP scores; not a significant difference.

If subjects completed the 9-week extension they had the option of enrolling in a double-blind 40-week extension study (placebo/asenapine $=32$, asenapine $=79$, and olanzapine $=107$ ), with the primary aim of assessing safety and tolerability (discussed in further detail below). ${ }^{21}$ At study end there was no statistical difference between asenapine and olanzapine on changes in the YMRS from baseline (asenapine $=-29$, olanzapine $=-28$ ), the CGI-BP (asenapine $=-3.6$, olanzapine $=-3.2$ ), or in MADRS scores (asenapine $=-4.8$, olanzapine $=-4.4$ ). At study end, the rates of YMRS response and remission for asenapine (95\%) and olanzapine (98\%) were not statistically different. There was no statistical difference in worsening of mania ( $\geq 25 \%$ increase in YMRS from baseline) between asenapine (2.6\%) and olanzapine (1.9\%).

The fifth pharmaceutical trial was 12 -week placebo controlled and conducted at 74 international sites. ${ }^{20}$ Asenapine was used as adjunctive therapy when subjects had an incomplete response to a mood stabilizer (lithium or valproate) in bipolar I disorder manic or mixed episodes (asenapine $=159$, placebo $=167)$. At week 3 , the asenapinetreated group showed a significant improvement on the YMRS compared to placebo, ${ }^{17}$ with no improvements seen in depression (MADRS). The study was extended for 40 weeks, and at 52 weeks no differences in change from baseline on the YMRS or MADRS compared to placebo were observed. ${ }^{20}$

Only one asenapine 3-week trial has reported on efficacy specifically by episode type (manic or mixed).$^{18}$ At day 2 , asenapine was significantly better than placebo on YMRS 
scores. No significant differences, although a trend, were observed for mixed episodes at day 21.

Patients not included in clinical trials include those under 18 or over 65 years old, those with bipolar II disorder, bipolar not otherwise specified, or those with rapid cycling and comorbid substance abuse. There may be differences in primary or secondary outcomes by ethnicity/race, as has been reported in other clinical trials. ${ }^{26}$

Overall the efficacy data on asenapine suggests that considering manic and mixed episodes together, there are significant decreases in manic symptoms after 21 days; however, olanzapine may have a more rapid effect on manic symptoms prior to 21 days. There was less benefit seen with depressive symptoms with asenapine than for olanzapine at day 21 for both 3-week trials, while in the long term there were no differences in depression symptoms between medications. In the long term, asenapine performed equally well to olanzapine across primary and secondary measures when used as monotherapy; however, as adjunctive therapy there may be no long-term benefit of asenapine on manic symptoms.

\section{Safety and tolerability}

The most common adverse reactions reported by patients ( $\geq 5 \%$ and at least twice the rate as placebo) in the monotherapy 3-week clinical trials were somnolence, dizziness, EPS other than akathisia and weight increase. ${ }^{18,19}$ Adverse effects from discontinuation of asenapine (at least $1 \%$ and twice the rate of placebo) are anxiety $(1.1 \%)$ and oral hypoesthesia (1.1\%) compared to placebo $(0 \%) .{ }^{18,19}$

Data from the 9-week extension show similar adverse effects: sedation, dizziness, and insomnia were the most commonly reported. ${ }^{22}$ Rates of EPS were similar in patients' first receiving placebo then asenapine (10\%), asenapine $(15 \%)$, and olanzapine (13\%); akathisia, tremor, and parkinsonism were the most prevalent.

In the 40-week extension the common adverse effects ( $\geq 10 \%$ in any treatment group) in the placebo/asenapine group were insomnia, headache, somnolence, nausea, parkinsonism, tremor, and constipation. ${ }^{21}$ Insomnia, sedation, depression, headache, somnolence, weight increase, dizziness, nausea, and akathisia were most common for the asenapine only group throughout the 3-, 9-, and 40-week trials. ${ }^{21}$ Table 1 provides a summary of adverse events across the clinical trials and includes a comparison to olanzapine for the 40-week trial.

\section{Metabolic outcomes}

Metabolic side effects are of great concern with atypical antipsychotics. The 3-week clinical trials reported a mean increase in fasting blood glucose $(n=379)$ similar to placebo $(\mathrm{n}=203)$ at $0.6 \mathrm{mg} / \mathrm{dL}$. The proportions of bipolar patients with fasting glucose elevations $\geq 126 \mathrm{mg} / \mathrm{dL}$ (at 3 weeks) was $4.9 \%$ in the asenapine-treated group versus $2.2 \%$ in placebo treated patients. The effect of asenapine on total cholesterol and triglycerides was a $1.1 \mathrm{mg} / \mathrm{dL}$ increase in total cholesterol versus a $1.5 \mathrm{mg} / \mathrm{dL}$ decrease in the placebo group and a $3.5 \mathrm{mg} /$ $\mathrm{dL}$ decrease in triglycerides versus a $17.9 \mathrm{mg} / \mathrm{dL}$ decrease in triglycerides in the placebo group. The proportion of patients with total cholesterol elevations $\geq 240 \mathrm{mg} / \mathrm{dL}$ (at 3-week endpoint) was $8.7 \%$ for asenapine-treated patients versus $8.6 \%$ for placebo-treated patients. The proportion of patients with elevations in triglycerides $\geq 200 \mathrm{mg} / \mathrm{dL}$ (at 3-week endpoint) was $15.2 \%$ for asenapine versus $11.4 \%$ for placebo.

In the 9-week extension study, patients treated with asenapine $(\mathrm{n}=181)$ had changes from baseline values of $-7.1 \pm 84.1 \mathrm{mg} / \mathrm{dL}$ in triglycerides, $2.2 \pm 21.6 \mathrm{mg} / \mathrm{dL}$ in fasting glucose, $-0.8 \pm 34.4 \mathrm{mg} / \mathrm{dL}$ in total cholesterol, $-1.5 \pm 26.3 \mathrm{mg} / \mathrm{dL}$ in low-density lipoprotein (LDL) cholesterol, and $1.5 \pm 10.0 \mathrm{mg} / \mathrm{dL}$ in high-density lipoprotein (HDL) cholesterol. Placebo/Asenapine-treated patients $(\mathrm{n}=94)$ had changes from baseline values of $-21.2 \pm 128.3 \mathrm{mg} /$ $\mathrm{dL}$ in triglycerides, $2.0 \pm 18.2 \mathrm{mg} / \mathrm{dL}$ in fasting glucose, $0.8 \pm 31.3 \mathrm{mg} / \mathrm{dL}$ in total cholesterol, $1.9 \pm 27.8 \mathrm{mg} / \mathrm{dL}$ in LDL cholesterol, $1.2 \pm 9.3 \mathrm{mg} / \mathrm{dL}$ in HDL cholesterol; and olanzapine treated patients $(n=229)$ had changes from baseline values of $30.1 \pm 115.9 \mathrm{mg} / \mathrm{dL}$ in triglycerides, $3.1 \pm 18.4 \mathrm{mg} / \mathrm{dL}$ in fasting glucose, $12.4 \pm 34.4 \mathrm{mg} / \mathrm{dL}$ in total cholesterol, $10.0 \pm 30.5 \mathrm{mg} / \mathrm{dL}$ in LDL cholesterol, $-1.2 \pm 11.2 \mathrm{mg} / \mathrm{dL}$ in HDL cholesterol.

By the end of the 40-week extension, patients treated with asenapine $(n=79)$ had changes from baseline values of $6.02 \mathrm{mg} / \mathrm{dL}$ in triglycerides, $-0.63 \mathrm{mg} / \mathrm{dL}$ in fasting glucose, $-4.56 \mathrm{mg} / \mathrm{dL}$ in total cholesterol, $-2.97 \mathrm{mg} / \mathrm{dL}$ in LDL cholesterol, and $-1.08 \mathrm{mg} / \mathrm{dL}$ in HDL cholesterol. Placebo/ Asenapine-treated patients $(n=32)$ had changes from baseline values of $-44.6 \mathrm{mg} / \mathrm{dL}$ in triglycerides, $2.47 \mathrm{mg} / \mathrm{dL}$ in fasting glucose, $7.61 \mathrm{mg} / \mathrm{dL}$ in total cholesterol, $8.69 \mathrm{mg} / \mathrm{dL}$ in LDL cholesterol, and $3.55 \mathrm{mg} / \mathrm{dL}$ in HDL cholesterol. Olanzapinetreated patients $(n=107)$ had changes from baseline values of $32.04 \mathrm{mg} / \mathrm{dL}$ in triglycerides, $7.12 \mathrm{mg} / \mathrm{dL}$ in fasting glucose, $16.99 \mathrm{mg} / \mathrm{dL}$ in total cholesterol, $13.44 \mathrm{mg} / \mathrm{dL}$ in LDL cholesterol, and $-2.39 \mathrm{mg} / \mathrm{dL}$ in HDL cholesterol.

Weight gain in the 3-week monotherapy registration trials was seen in $5 \%$ of asenapine-treated patients versus $<1 \%$ for placebo. Weight gain during the 9-week extension trial showed clinically significant weight gain ( $\geq 7 \%$ increase from baseline) in 19\% of asenapine-, $10 \%$ placebo/asenapine-, and 
Table I Side effect profiles across four clinical trials of asenapine

\begin{tabular}{|c|c|c|c|c|}
\hline Side effects & $\begin{array}{l}3 \text { weeks }^{b} \\
(n=379)(\%)\end{array}$ & $\begin{array}{l}4-12 \text { weeks }^{c} \\
(n=\mid 8 I)(\%)\end{array}$ & $\begin{array}{l}\text { I3-52 weeks } \\
(n=79)(\%)\end{array}$ & $\begin{array}{l}\text { Olanzapine } \\
\text { I3-52 weeks } \\
(n=107)(\%)\end{array}$ \\
\hline Sedation & 14 & 14 & 17 & 16 \\
\hline Somnolence & 14 & 12 & 14 & 16 \\
\hline Insomnia & - & 13 & 20 & 12 \\
\hline Headache & - & 21 & 14 & 14 \\
\hline Dizziness & 11 & 24 & 13 & 6 \\
\hline Nausea & - & 8 & 13 & 13 \\
\hline Constipation & - & 10 & 6 & 6 \\
\hline Dry mouth & 4 & 7 & - & - \\
\hline Vomiting & 5 & - & - & - \\
\hline Appetite increase & 4 & - & - & - \\
\hline Depression & - & - & 15 & 8 \\
\hline \multicolumn{5}{|l|}{ Metabolic ${ }^{\mathrm{a}}$} \\
\hline Weight gain & 7 & 19 & 31 & 55 \\
\hline $\begin{array}{l}\text { Blood glucose levels } \\
\text { (elevated or decreas }\end{array}$ & \multicolumn{3}{|c|}{ (elevated or decreased levels) } & 22 \\
\hline Triglycerides & 0 & - & - & - \\
\hline Weight loss & 2 & 7 & - & - \\
\hline Prolactin & 0 & 3 & 3 & 3 \\
\hline \multicolumn{5}{|l|}{ EPS } \\
\hline Tremor & - & - & 8 & 5 \\
\hline Akathisia & 4 & - & 11 & 10 \\
\hline Parkinsonism & 2 & - & 8 & 4 \\
\hline Dystonia & 4 & - & 4 & I \\
\hline Bradykinesia & 2 & - & 4 & 2 \\
\hline Dyskenisia & I & - & 1 & 0 \\
\hline Gait disturbance & 0 & - & 3 & 0 \\
\hline Masked facies & - & - & I & 0 \\
\hline Tardive dyskinesia & - & - & 3 & 0 \\
\hline
\end{tabular}

Notes: aPercentages denote clinically significant changes; baverage of 3-week trial data; 'percentages do not include the placebo/asenapine group that started asenapine after a 3-week delay.

Abbreviation: EPS, extrapyramidal symptoms.

$31 \%$ olanzapine-treated patients. ${ }^{22}$ In the 40 -week extension, clinically significant weight gain ( $\geq 7 \%$ increase from baseline) occurred in $39.2 \%$ of asenapine-treated patients, $21.9 \%$ placebo/asenapine, and $55.1 \%$ of olanzapine-treated patients. Eighteen percent of the subjects in the 40 -week extension trial had clinically significant changes in fasting blood glucose levels.
Table 1 provides a summary of side effects and clinically significant metabolic outcomes across studies. In the longterm asenapine users, many continue to have somnolence, sedation, insomnia, headaches, and other side effects including EPS although these effects are similar to what is observed in olanzapine. Over time, asenapine has a more favorable profile for weight gain than olanzapine. The laboratory findings

Table 2 Summary of efficacy and discontinuation data for asenapine using last observation carried forward analyses

\begin{tabular}{|c|c|c|c|c|}
\hline & $\begin{array}{l}\text { 3-week trial } \\
(n=185) \\
7501004\end{array}$ & $\begin{array}{l}\text { 3-week trial } \\
(n=194) \\
7501005\end{array}$ & $\begin{array}{l}9 \text { weeks }^{c} \\
(n=275)\end{array}$ & $\begin{array}{l}40 \text { weeks }^{c} \\
(n=I I 2)\end{array}$ \\
\hline Efficacy & \multicolumn{4}{|c|}{ Mean change from baseline \pm standard deviation } \\
\hline YMRS & $-I I .5 \pm 0.8^{\mathrm{a}, \mathrm{b}}$ & $-10.8+0.8^{\mathrm{a}}$ & $-24.4 \pm 8.7$ & $-25.8 \pm 10.3$ \\
\hline Clinical global impression for bipolar disorder & $-1.2 \pm 0.10^{\mathrm{a}, \mathrm{b}}$ & $-1.2+0.1^{\mathrm{a}}$ & $-2.8 \pm 0.09$ & $-3.2 \pm 1.3$ \\
\hline Montgomery-Asberg depression rating scale & $-3.0 \pm 0.4$ & $-3.2+0.5$ & $-3.6 \pm 0.69$ & $-4.8 \pm 6.5$ \\
\hline Response ( $\geq 50 \%$ improvement on YMRS) & $78(43 \%)$ & $81(42 \%)^{a}$ & $212(77 \%)$ & $110(98 \%)^{d}$ \\
\hline Remission ( $\leq 12$ YMRS) & $67(36 \%)$ & $78(40 \%)^{\mathrm{a}}$ & $206(75 \%)$ & $110(98 \%)^{d}$ \\
\hline Dropout rates & $61(33 \%)$ & $72(37 \%)$ & 113 (4I\%) & $46(41 \%)$ \\
\hline
\end{tabular}

Notes: aDiffers from placebo; ${ }^{b}$ differs from olanzapine favoring olanzapine; ${ }^{n}$ no placebo group; ${ }^{d}$ response and remission rates were reported as one percentage. Abbreviation: YMRS, Young mania rating scale. 
suggest that asenapine does not have profound effects, but weight gain, fasting glucose, and lipids should be monitored closely. It is also important to note that the more commonly reported range for fasting glucose is $>110 \mathrm{mg} / \mathrm{dL}$, the range cholesterol elevations is $\geq 200 \mathrm{mg} / \mathrm{dL}$, and the range for elevated triglycerides is $\geq 150 \mathrm{mg} / \mathrm{dL}^{27}$

\section{Patient acceptability}

Study dropout rates putatively take into account both efficacy and adverse effects and thus overall tolerability of a medication. Ten percent of asenapine treated patients $(n=38 / 379)$ in the 3-week trials discontinued treatment due to adverse events, compared to $6 \%$ on placebo $(n=12 / 203)$. In 3 -week trial 7501004, completion rates were as follows: 58\% placebo, $67 \%$ asenapine, and $79 \%$ olanzapine. For asenapine, adverse events and mania were the most frequent reasons for leaving the trial. Of serious adverse events, 9 of 12 were worsening of disease (placebo 5 of 7, olanzapine 3 of 8). Subjects were significantly more likely to complete the trial when taking olanzapine. ${ }^{19}$ In 3-week trial 7501005, completion rates were as follows: $62 \%$ placebo, $63 \%$ asenapine, and $80 \%$ olanzapine ${ }^{18}$ the completion rate was significantly higher with olanzapine. The most frequent reasons for discontinuation of asenapine were $8 \%$ lack of efficacy, $10 \%$ adverse events (mania was the most common adverse event), and 14\% withdrew their consent. Mania as an adverse event was rated independently from lack of efficacy, so the subject could have had both reasons coded for dropout per clinician impression.

Over the 40 -week trial, $40 \%$ of the placebo/asenapine subjects completed the study, $65.8 \%$ of the asenapine subjects, and $63.6 \%$ of the olanzapine group. ${ }^{21}$ Discontinuation rates due to adverse events were highest in the placebo/asenapine group ( $\mathrm{n}=5,15.6 \%$ of dropouts) but were comparable in the asenapine $(n=7,8.9 \%)$ and olanzapine $(n=9,8.4 \%)$ groups. Among all patients who received asenapine, the discontinuation rate due to adverse events was $11 \%$ while discontinuation due to lack of efficacy averaged $41 \%$ across patients taking asenapine.

Sexual dysfunction is a concern for individuals with bipolar disorder taking antipsychotic medications, ${ }^{28}$ and may be a hidden cause of nonadherence to antipsychotic medication. ${ }^{29}$ Noen of the trials reported sexual side effects. One patient acceptability concern with asenapine is the sublingual administration and the requirement of no food or water for 10 minutes after administration. ${ }^{30}$ Asenapine is dosed twice daily, which may be more challenging than once daily regimens. Some patients with cognitive difficulties such as memory or disorganization may have difficulties adhering to this regimen. Some individuals anecdotally report bad taste of the medication and/or oral hypoesthesia.

\section{Metabolism}

Asenapine has been found to be a weak inhibitor of cytochrome P-450 2D6, so major drug interactions are not expected; but it should be used with caution with other agents that are metabolized by CYP 2D6 (eg, paroxetine, most tricyclic antidepressants, amoxapine, captopril, duloxetine, fluoxetine, fluvoxamine, haldol). Co-administration of a single 20-mg dose of paroxetine during treatment with $5 \mathrm{mg}$ asenapine twice daily in 15 healthy male subjects resulted in an almost 2-fold increase in paroxetine exposure. ${ }^{17}$ Asenapine may enhance the inhibitory effects of paroxetine on its own metabolism. Also since asenapine is metabolized by CYP 1A2, caution should be used with co-administration with agents/conditions that induce CYP $1 \mathrm{~A} 2$ (eg, smoking, carbamazepine, or rifampin) or inhibit CYP 1A2 (eg, fluvoxamine, ciprofloxacin, or ketoconazole).

Asenapine does not require any dosage adjustment in renal impairment. In severe hepatic impairment (Child-Pugh C), asenapine is not recommended. Asenapine levels were 7-fold higher in patients with Child-Pugh $\mathrm{C}$ classified hepatic impairment versus patients with normal hepatic function.

\section{Black box warning}

As is the case for all antipsychotic medications prescribed to elderly individuals, there is a black box warning for asenapine. Elderly patients with dementia-related psychosis treated with antipsychotic drugs are at an increased risk of death, due to cerebrovascular adverse reactions including fatalities.

\section{Discussion}

Asenapine is a recently FDA-approved atypical antipsychotic which has shown benefits in treating manic and mixed states as monotherapy in bipolar disorder up to one year after initiation of treatment. In two 3-week trials, asenapine had a higher dropout rate than olanzapine, often due to continuing manic symptoms. After 3 weeks, asenapine performs as well as olanzapine on primary efficacy outcomes. In a trial to assess the adjunctive effects of asenapine on manic and mixed states, there were short-term benefits on manic symptoms, but no additional benefits in the longterm for asenapine versus placebo as adjunctive therapy. ${ }^{20}$ Asenapine is FDA approved to treat manic and mixed episodes in bipolar disorder. However, asenapine may be 
less effective for mixed states in the short-term. Only one asenapine 3-week trial reported by subgroup, and they noted significant improvements at day 2 compared to placebo, with the improvement not statistically significant compared to placebo by day 21 . Additional subgroup analyses on mixed states would be beneficial.

Asenapine did not show improvement on depressive symptoms in the short term or long term. During the 40 -week extension period, $15 \%$ of subjects had worsening of depression symptoms while $8 \%$ of the olanzapine group had worsening symptoms. Thus, one of the primary interests of new pharmaceuticals from a patient's perspective (ie, treating depressive symptoms) ${ }^{15}$ is not addressed by asenapine. Weight gain was the other patient-expressed concern. Greater weight gain in the olanzapine group emerged in the initial 3-week trials. In a year's time, 31\% of the asenapine group had clinically significant weight gain, as compared with $55 \%$ with olanzapine. Compared with olanzapine, asenapine has a more favorable weight gain side effect profile although both compounds have a significant impact on weight. Elevated fasting blood glucose levels were comparable in asenapine and olanzapine in the long-term trial. Monitoring of lab values and metabolic outcomes with asenapine is crucial.

Long-term side effects reported by at least $10 \%$ of the asenapine group are sedation, somnolence, insomnia, headache, dizziness, nausea, and akathisia. Tremor and parkinsonism were reported by $8 \%$ of subjects. None of the clinical trials reported the frequency or seriousness of sexual dysfunction while taking asenapine. Sexual dysfunction may be a hidden cause of nonadherence to antipsychotic medication ${ }^{28,29}$ as clinicians may underestimate the frequency of sexual side effects. Further attention to this topic in future trials is warranted. A consideration of these side effects in prescribing asenapine will be essential to adherence to the treatment regimen. Table 3 provides an overview of side effect profiles across medications used to treat bipolar disorder.

Other antipsychotics might have similar or more favorable weight gain profiles. In a 3-week trial, weight gain for risperidone (3.53 pounds) was significantly less than for olanzapine (5.42 pounds). ${ }^{31}$ In a 6-month trial of risperidone to treat mania in bipolar disorder, the average weight gain was 7.05 pounds with $9 \%$ of subjects gaining more than $7 \%$ of their body weight. ${ }^{32}$ In 8 -week studies of quetiapine in bipolar disorder, average weight gain was 2.2 to 3.53 pounds. ${ }^{33}$ Studies of asenapine in schizophrenia show lower weight gain profiles than other atypical antipsychotics; ${ }^{34}$ however, these studies are not directly comparable to bipolar disorder where the dose is typically double that of the schizophrenia trials ( $10 \mathrm{mg}$ versus $20 \mathrm{mg}$ total daily dose). Table 3 provides an overview of weight gain comparisons across several antipsychotics.

\section{Clinical situations where asenapine may be the preferred agent}

Asenapine was recently introduced and the clinical indications, which may distinguish it from other treatments of mania, are lacking. The pharmacology of asenapine offers a commonsense approach to guide its use. One benefit of asenapine for some patients is the sublingual application, a preferred option for patients who cannot take medications by tablet because of medical or behavioral reasons, for example, a patient who cannot swallow pills due to an esophageal stricture, gastric bypass surgery, or general unwillingness to swallow pills. Other areas where sublingual medication is especially important include crisis intervention requiring rapid onset, or with patients who may be reluctant to take medication, such as an inpatient setting or forensic setting where patients may

Table 3 Side effect profiles of antipsychotics in adults with bipolar disorder

\begin{tabular}{|c|c|c|c|c|c|c|c|}
\hline & FDA indication & Sedation & $\begin{array}{l}\text { Weight } \\
\text { gain }\end{array}$ & Diabetes & EPS & $\begin{array}{l}\text { Prolactin } \\
\text { elevation }\end{array}$ & $\begin{array}{l}\text { QTc } \\
\text { prolongation }\end{array}$ \\
\hline Aripiprazole & Manic/mixed episodes and maintenance & - & $+/-$ & - & + & - & - \\
\hline Asenapine & Manic/mixed episodes & ++ & ++ & ++ & + & $+1-$ & + \\
\hline Chlorpromazine & Mania & +++ & ++ & ++ & ++ & ++ & ++ \\
\hline Haloperidol & Psychosis & + & + & + & +++ & +++ & + \\
\hline Olanzapine & Manic/mixed episode and maintenance & ++ & +++ & +++ & $+1-$ & + & + \\
\hline Quetiapine & $\begin{array}{l}\text { Manic episodes and depressive episodes } \\
\text { and maintenance }\end{array}$ & ++ & ++ & ++ & - & - & ++ \\
\hline Risperidone & Manic/mixed episodes & + & + & ++ & $++/+$ & +++ & + \\
\hline Ziprasidone & Manic/mixed episodes & + & $+1-$ & - & $+1-$ & $+1-$ & ++ \\
\hline
\end{tabular}

Notes: +++, very common side effect; ++, common side effect; +, less common side effect; -, uncommon side effect. Abbreviations: EPS, extrapyramidal symptoms; FDA, US Food and Drug Administration. 
not swallow medication but rather hold it in their mouth (ie, "cheek it").

The other treatment guidance comes from asenapine's pharmacological profile. ${ }^{35}$ Asenapine has relatively low histamine receptor $1\left(\mathrm{H}_{1}\right)$ affinity. Histamine receptor blockade is often implicated in atypical antipsychotic-induced weight gain and sedation, suggesting less weight gain and sedation liability than atypical antipsychotics with high $\mathrm{H}_{1}$ affinity (such as olanzapine or quetiapine). Additionally, it has lower affinity for dopamine receptors 1,2 ( $\left.\mathrm{D}_{1,2}\right)$ suggesting it will have less extrapyramidal and hyperprolactinemia effects than haloperidol. These attributes should be considered with individuals who are at risk for developing metabolic syndrome and when other medications were stopped due to intolerable side effects, eg, akathisia. Another clinical situation where asenapine may be a good choice is with QT prolongation, which asenapine is less apt to produce than ziprasidone. ${ }^{36}$ Finally, there is a growing awareness that anxiety in mood disorders increases the severity of the illness. ${ }^{37,38}$ While there are no published trials of asenapine treatment of bipolar disorder and anxiety, asenapine acts as an inverse agonist at the serotonin $1 \mathrm{~A}\left(5 \mathrm{HT}_{1 \mathrm{~A}}\right)$ receptor, similar to anxiolytic busperoine ${ }^{39}$ suggesting that patients with anxiety may benefit from its use.

\section{Potential asenapine contraindications}

Patients who have demonstrated nonadherence in the initial 3 weeks of treatment due to slow medication effects may fare better with a faster acting medication such as olanzapine. For patients who have cognitive deficits interfering with adherence to a slightly more complex regimen than other atypical antipsychotics (ie, twice daily and food intake restrictions) asenapine may not be the preferred agent. As there is increased risk of metabolic syndrome for asenapine, consideration of comorbid medical conditions is essential, that is, diabetes and any indications of metabolic syndrome. In these cases, other antipsychotics should be considered first (eg, aripiprazole, ziprasidone). Other comorbid conditions to carefully consider are any hepatic impairment or any comorbid conditions, which include medication regimens that may be contraindicated in asenapine administration. Asenapine may be less indicated for mixed states only, for long-term use as adjunctive therapy, or for those patients and clinicians who may also be looking for a medication with a potential antidepressant effect.

In this review we provide information on reasons for dropout, typical side effects to expect with asenapine, and discuss issues related to adherence to antipsychotics in general. However, this report is limited by the current lack of studies examining patient preferences and issues related to adherence with asenapine.

\section{Conclusion}

Asenapine shows promise as an option in bipolar disorder manic or mixed states. The side effect profile and medication administration requirements should be considered with each individual where treatment is indicated. The initial side effects to be expected and how to manage them should be discussed in detail by the clinician. Patients should be reminded that it might take weeks to experience the full impact of the medication. In prescribing antipsychotics, a general review of barriers to adherence is recommended, such as discussing with each patient what might interfere with taking the medicine, how they will remember to take the medicine, and how they will manage initial side effects. Close follow up at initial stages of treatment to track barriers to adherence is recommended. There are a range of side effects and laboratory measures that will need to be monitored in prescribing asenapine, as is the case for all atypical antipsychotics.

\section{Disclosure}

The authors declare no conflicts of interest in relation to this paper.

\section{References}

1. Grunze H, Kasper S, Goodwin G, Bowden C, Moller HJ. The World Federation of Societies of Biological Psychiatry (WFSBP) guidelines for the biological treatment of bipolar disorders, part III: maintenance treatment. World J Biol Psychiatry. 2004;5:120-135.

2. Hirschfeld RMA. Guideline Watch: Practice Guideline for the Treatment of Patients with Bipolar Disorder. 2nd ed. Arlington, VA: American Psychiatric Association; 2005.

3. Berk L, Hallam KT, Colom F, et al. Enhancing medication adherence in patients with bipolar disorder. Hum Psychopharmacol. 2010;25: $1-16$.

4. Perlis RH, Ostacher MJ, Miklowitz DJ, et al. Clinical features associated with poor pharmacologic adherence in bipolar disorder: results from the STEP-BD study. J Clin Psychiatry. 2010;71:296-303.

5. Scott J, Pope M. Self-reported adherence to treatment with mood stabilizers, plasma levels, and psychiatric hospitalization. Am J Psychiatry. 2002;159:1927-1929.

6. Pope M, Scott J. Do clinicians understand why individuals stop taking lithium? J Affect Disord. 2003;74:287-291.

7. Sajatovic M, Davies M, Hrouda DR. Enhancement of treatment adherence among patients with bipolar disorder. Psychiatr Serv. 2004;55: 264-269.

8. Velligan DI, Weiden PJ, Sajatovic M, et al. The expert consensus guideline series: adherence problems in patients with serious and persistent mental illness. J Clin Psychiatry. 2009;70(Suppl 4): $1-46$.

9. Gutierrez-Rojas L, Jurado D, Martinez-Ortega JM, Gurpegui M. Poor adherence to treatment associated with a high recurrence in a bipolar disorder outpatient sample. J Affect Disord. 2010;127(1-3):77-83. 
10. Scott J, Tacchi MJ. A pilot study of concordance therapy for individuals with bipolar disorders who are non-adherent with lithium prophylaxis. Bipolar Disord. 2002;4:386-392.

11. Haddad PM, Sharma SG. Adverse effects of atypical antipsychotics: differential risk and clinical implications. CNS Drugs. 2007;21:911-936

12. Wilder CM, Elbogen EB, Moser LL, Swanson JW, Swartz MS Medication preferences and adherence among individuals with severe mental illness and psychiatric advance directives. Psychiatr Serv. 2010;61:380-385.

13. Sajatovic M, Jenkins JH. Is antipsychotic medication stigmatizing for people with mental illness? Int Rev Psychiatry. 2007;19:107-112.

14. Johnson FR, Ozdemir S, Manjunath R, Hauber AB, Burch SP, Thompson TR. Factors that affect adherence to bipolar disorder treatments: a stated-preference approach. Med Care. 2007;45:545-552.

15. McIntyre RS. Understanding needs, interactions, treatment, and expectations among individuals affected by bipolar disorder or schizophrenia the UNITE global survey. J Clin Psychiatry. 2009;70(Suppl 3):5-11.

16. Newcomer JW, Haupt DW. The metabolic effects of antipsychotic medications. Can J Psychiatry. 2006;51:480-491.

17. Saphris ${ }^{\circledR}$ (Asenapine). [Package insert.] Kenilworth, NJ: ScheringPlough (Merck and Co, Inc); 2011.

18. McIntyre RS, Cohen M, Zhao J, Alphs L, Macek TA, Panagides J. A 3-week, randomized, placebo-controlled trial of asenapine in the treatment of acute mania in bipolar mania and mixed states. Bipolar Disord. 2009;11:673-686.

19. McIntyre RS, Cohen M, Zhao J, Alphs L, Macek TA, Panagides J. Asenapine in the treatment of acute mania in bipolar I disorder: a randomized, double-blind, placebo-controlled trial. J Affect Disord. 2010;122: 27-38.

20. Calabrese J, Stet L, Kotari H, et al. Asenapine as adjunctive treatment for bipolar mania: results of a placebo-controlled 12-week study and 40-week extension [abstract]. Proceedings of the163rd Annual Meeting of the American Psychiatric Association; 2010 May 22-26; New Orleans, LA. Red Hook, NY: Curran Associates.

21. McIntyre RS, Cohen M, Zhao J, Alphs L, Macek TA, Panagides J. Asenapine for long-term treatment of bipolar disorder: a double-blind 40-week extension study. J Affect Disord. 2010;126:358-365.

22. McIntyre RS, Cohen M, Zhao J, Alphs L, Macek TA, Panagides J. Asenapine versus olanzapine in acute mania: a double-blind extension study. Bipolar Disord. 2009;11:815-826.

23. Young RC, Biggs JT, Ziegler VE, Meyer DA. A rating scale for mania: reliability, validity and sensitivity. Br J Psychiatry. 1978;133:429-435.

24. Guy W. Clinical global impressions. In: Guy W, editor. ECDEU Assessment Manual for Psychopharmacology. Washington, DC: US Department of Health, Education and Welfare; 1976.
25. Montgomery SA, Asberg M. A new depression scale designed to be sensitive to change. Br J Psychiatry. 1979;134:382-389.

26. Tamayo JM, Mazzotti G, Tohen M, et al. Outcomes for Latin American versus White patients suffering from acute mania in a randomized, doubleblind trial comparing olanzapine and haloperidol. J Clin Psychopharmacol. 2007;27:126-134.

27. US Department of Health and Human Services. Adult Treatment Panel III (ATP III) of the National Cholesterol Education Program.01-3305. 2001. National Institutes of Health.

28. Brooks JO III, Goldberg JF, Ketter TA, et al. Safety and tolerability associated with second-generation antipsychotic polytherapy in bipolar disorder: findings from the Systematic Treatment Enhancement Program For Bipolar Disorder. J Clin Psychiatry. 2011;72:240-247

29. Baldwin D, Mayers A. Sexual side effects of antidepressant and antipsychotic drugs. Adv Psychiatr Treat. 2003;9:202-210.

30. [No authors listed.]Asenapine (Saphris) sublingual tablets for schizophrenia and bipolar disorder. Med Lett Drugs Ther. 2010;52:9.

31. Perlis RH, Baker RW, Zarate CA Jr, et al. Olanzapine versus risperidone in the treatment of manic or mixed states in bipolar I disorder: a randomized, double-blind trial. J Clin Psychiatry. 2006;67:1747-1753.

32. Vieta E, Brugue E, Goikolea JM, et al. Acute and continuation risperidone monotherapy in mania. Hum Psychopharmacol. 2004;19: $41-45$.

33. Bogart GT, Chavez B. Safety and efficacy of quetiapine in bipolar depression. Ann Pharmacother. 2009;43:1848-1856.

34. Potkin SG, Cohen M, Panagides J. Efficacy and tolerability of asenapine in acute schizophrenia: a placebo- and risperidone-controlled trial. J Clin Psychiatry. 2007;68:1492-1500.

35. Shahid M, Walker GB, Zorn SH, Wong EH. Asenapine: a novel psychopharmacologic agent with a unique human receptor signature. J Psychopharmacol. 2009;23:65-73.

36. Glassman AH. Schizophrenia, antipsychotic drugs, and cardiovascular disease. J Clin Psychiatry. 2005;66(Suppl 6):5-10.

37. Diefenbach GJ, Woolley SB, Goethe JW. The association between selfreported anxiety symptoms and suicidality. J Nerv Ment Dis. 2009;197: 92-97.

38. Dilsaver SC, Akiskal HS, Akiskal KK, Benazzi F. Dose-response relationship between number of comorbid anxiety disorders in adolescent bipolar/unipolar disorders, and psychosis, suicidality, substance abuse and familiality. J Affect Disord. 2006;96:249-258.

39. Ghanbari R, El Mansari M, Shahid M, Blier P. Electrophysiological characterization of the effects of asenapine at 5-HT(1 A), 5-HT(2 A), alpha(2)adrenergic and D(2) receptors in the rat brain. Eur Neuropsychopharmacol. 2009;19:177-187.
Patient Preference and Adherence

\section{Publish your work in this journal}

Patient Preference and Adherence is an international, peer-reviewed, open access journal focusing on the growing importance of patient preference and adherence throughout the therapeutic continuum. Patient satisfaction, acceptability, quality of life, compliance, persistence and their role in developing new therapeutic modalities and compounds to

\section{Dovepress}

optimize clinical outcomes for existing disease states are major areas of interest. This journal has been accepted for indexing on PubMed Central. The manuscript management system is completely online and includes a very quick and fair peer-review system. Visit http://www.dovepress.com/ testimonials.php to read real quotes from published authors. 